\title{
Att bedriva sociologisk forskning $i$ en tid av byråkratiserad etikprövning
}

SVERIGE ÄR ETT få länder i världen som reglerar forskningsetik i lag (Eldén 2020). Men vad händer när en enhetlig lagstiftning inte har hänsyn till olika forskningsdiscipliners särart, och forskningsetiken formaliseras i ämnesövergripande förordningar? Den formella process som etikprövning av forskning har utvecklats till kan innebära en utmaning för möjligheten att bedriva sociologisk forskning, både vad gäller anpassning till en byråkratisk diskurs och i kontakten med respondenter.

Det här samtalet baseras på ett seminariesamtal som organiserades av sociologiämnet på Södertörns högskola den 17 november 2021, där Jonas Edlund, professor i sociologi vid Umeå universitet, Sara Eldén, docent och lektor i sociologi vid Lunds universitet och David Wästerfors, professor i sociologi vid Lunds universitet deltog. En av tidskriftens redaktörer, Lena Sohl, var moderator. Ania Hartman bistod med att omvandla samtalet till en transkriberad text, som sedan har redigerats av Lena Sohl. Forskarna har kunnat ändra och göra tillägg i sina svar.

Jonas Edlund arbetar främst med kvantitativa metoder. Hans forskningsintressen rör politisk sociologi och social stratifiering. Han är ansvarig för den svenska delen av International Social Survey Program (ISSP). Sara Eldéns forskningsinriktning är omsorgs-, barn- och familjesociologi samt utvecklandet av innovativa kvalitativa metoder. Hon gav 2020 ut boken Forskningsetik. Vägval i samhällsvetenskapliga studier. David Wästerfors forskning behandlar frågor som rör sig i fälten kultursociologi, kriminologi och socialpsykologi. Han utgår i sin forskning från erfarenhetsnära material, exempelvis kvalitativa intervjuer, och publicerade 2019 artikeln "Den etnografiskt okänsliga etikgranskningen".

Bakgrunden till att samtalet hölls är att processen för att ansöka om etikprövning har förändrats mycket de senaste åren. Kraven har blivit mer omfattande. Ett forskningsprojekt måste i dag formuleras utifrån de specifika termer som används i tolkningen av lagstiftningen, bland annat när det gäller GDPR och hanteringen av känsliga personuppgifter. Ett instrument som var tänkt att skydda respondenter från kränkning riskerar nu att försvåra viss typ av forskning och kan av forskarna upplevas som ett instrument som reglerar forskningens inriktning och möjliga frågeställningar.

Det är inte heller alla forskningsfrågor och datainsamlingsmetoder som självklart kan anpassas till denna process. Till exempel är det svårt att i förväg beskriva alla steg 
i vissa kvalitativt inriktade forskningsprojekt, där fältarbetets samspel med människor kan leda projektet i nya riktningar. Vid kontakter med respondenter riskerar dessutom kraven på att ett byråkratiskt språk ska användas, exempelvis i informationsbrev, att skapa misstro och skrämma bort respondenter. Detta gäller särskilt grupper av respondenter som inte är vana vid byråkratiskt språk eller uppfattar det som ett maktspråk.

En ytterligare aspekt är att Etikprövningsmyndighetens ansökningsförfarande är utformat utifrån etiska överväganden som främst är relevanta för medicinsk forskning, men som ofta är mindre relevanta för samhällsvetenskaplig forskning. Givet att etikprövning av samhällsvetenskaplig forskning främst motiveras av hanteringen av känsliga personuppgifter eller personuppgifter om lagöverträdelser kan det tyckas märkligt att ansökningsförfarandet inte diversifieras utifrån bredare ämnesdiscipliner och de forskningsmetoder som är grundläggande inom dessa.

Sociologisk Forskning: Sverige är ett av få länder i världen där forskningsetik regleras i lag. Etikprövningslagen har dessutom sedan den trädde i kraft 2004 reviderats flera gånger. Studentarbeten har uteslutits och nya skrivningar har tillkommit, som behandling av personuppgifter 2018. Jag undrar vad ni tycker om dagens etikprövningssystem? I anslutning till den frågan undrar jag också vad ni tycker om de förändringar som etikprövningssystemet har genomgått och konsekvenserna av de förändringarna, som att etikprövningen har blivit mer omfattande och att man efterfrågar allt fler uppgifter från forskare?

Sara Eldén: Ja, det är en stor fråga och vi tycker och känner mycket inför det här systemet, alla vi forskare som har haft att hantera det. Men om man tittar på historien om forskningsetik så tänker jag att det finns vissa saker, som är viktiga för att förstå dagens system. Regleringen i Sverige, eller i världen, har i hög grad styrts av den medicinska forskningens praktiker och av den medicinska forskningens skandaler. Det gör att den ofta formas utifrån en slags worst case scenarios. Det kan vi se var fallet vid den senaste ändringen av etikprövningslagen, som skedde för ett par år sedan, där Macchiarini-affären fanns i bakgrunden. Som en bisats kan man fundera över om Macchiarini-affären egentligen handlade så mycket om forskningsetik. Självklart bröt han mot forskningsetiken, men jag kan tycka det finns många andra dimensioner. Det handlar också om hur universitetet är uppbyggt, konkurrensen och sökandet efter superhjälteforskare som ska excellera och hur det trubbar av vår kritiska udd gentemot varandra på ett mer fundamentalt plan än att försöka reglera saker i lag och utse bovar som bryter mot uppställda regler. Därmed inte sagt att han inte bröt mot forskningsetik, det är ingen tvekan om det, men det handlar om fler saker.

Men det är intressant att det är så vi går in i det: efter skandalerna går vi in och ska reglera. Då tror vi oss kunna komma till rätta med allt, men jag tror inte att det är så enkelt. Jag tror att det handlar om mycket större strukturer kring hur vi bygger upp forskning, hur vi tänker kring forskning och konkurrens inom forskningen och så vidare. Infrastrukturen kring forskningsetik i Sverige, systemet som vi har i dag, har kommit att präglas mer och mer av att vi förhåller oss till det legala. Det finns en 
stark deontologisk syn på etik här, vi ska kunna följa på förhand uppsatta regler och på så sätt ska vi ska bli mer etiska. Detta tror jag leder oss in i tron att etik handlar om enkla rätt och fel, och det gör det faktiskt ganska sällan i praktiken. Effekten blir att vi betonar den prospektiva etiken och tappar den emergenta. Vi förleds att tro att vi är klara med etik när etikprövningen är över. Vi utvecklar en kompetens för att klara oss igenom, vi delar med oss av råd för hur vi ska göra etikprövningen, hur vi ska skriva och fylla i blanketten. Det är jättebra att tänka igenom saker innan ett forskningsprojekt ska genomföras, men etikprövningens blankett leder oss kanske inte alltid in på rätt frågor. Än värre är att vi förleds att tro att etik handlar om att enkelt följa det här protokollet, och att det oförutsägbara, de emergenta dilemmana som vi faktiskt ställs inför i praktiken, hamnar i skymundan. Dem blir vi på så sätt lämnade ensamma med. Så det tänker jag är en negativ effekt av dagens system.

Sedan finns också ett ökat inslag av övervakning. Sociologin utsågs 2021 till att granskas av Överklagandenämnden för etikprövning. Det här ger forskare känslan av att vara övervakade och att vi kan begå brott, fast vi kanske inte ens riktigt är medvetna om att det vi gjort är ett brott. Vårt professionella omdöme kan säga oss att man exempelvis ibland behöver avvika från en tänkt forskningsdesign, att kanske fler eller färre eller andra människor än de man tänkt på från början och angivit i etikprövningen behöver involveras. Det kan i vissa fall ses som en "avvikelse" som gör att vi bryter mot lagen. Om jag då ändå ska nämna en positiv sak med nuvarande system är det att vi faktiskt pratar mer om etik generellt i dag, när vi uppmärksammar att det här systemet inte fungerar för oss samhällsvetare alla gånger. Kanske kan detta att vi talar mer om etik göra att vi också uppmärksammar sådant som vi faktiskt gör som inte är så etiskt, utan är problematiskt i olika praktiker som vi ägnar oss åt. Sådant som behöver funderas igenom, om än inte nödvändigtvis utifrån de premisser som Etikprövningsmyndigheten eller etikprövningsinfrastrukturen ställer upp, men vi pratar ändå mer om etik.

\section{Sociologisk Forskning: Jonas, du jobbar ju med kvantitativa data i betydligt högre grad än vad Sara gör. Vad säger du om detta utifrån ditt perspektiv och de frågor som du jobbar med?}

Jonas Edlund: Ja, jag tycker att den här förändringen 2018 har gjort det mycket besvärligare. Jag håller med om allting du sade Sara. Just det här med att man utgår från regler och gör att man kanske glömmer bort ibland att tänka på vad som egentligen är etiskt, alltså hur ska man bete sig som forskare? Men det rent konkreta när det gäller den kvantitativa forskningen är att den aldrig har varit intresserad av enskilda personer egentligen. Det har alltid varit fråga om grupper och aggregerade data. Det har alltid varit så att om någon skulle vilja baklängesidentifiera personer, som när man har hela datamatrisen framför sig och kan se att här är en som är si och så gammal, bor där eller där, tycker si och så om något, så kan det i och för sig gå i vissa mycket speciella fall, men det är ju ändå inte det som är poängen med kvantitativ forskning. Sedan tycker jag att det är märkligt att det är just forskningen som sätts under de här hårda kraven, 
medan den privata sektorn med sina marknadsundersökningar eller journalistiken inte berörs på samma sätt. Det är kanske ändå där inom massmedia och journalistiken de flesta övergreppen mot individer har gjorts, så det här misstänkliggörandet av forskning har jag lite svårt för. Men nu måste vi förhålla oss till det som är. Då kan jag knyta an till det du sade i början Lena, om att i Sverige har vi, om jag har förstått det rätt, gått väldigt långt $\mathrm{i}$ en mycket strikt tolkning av GDPR till exempel, vilket inte skett i andra EU-länder.

David Wästerfors: Jag håller med om vad Sara och Jonas säger så jag vet inte om jag har så mycket att tillägga. Jag har väl tre iakttagelser. Den första gäller kontrasten mellan etiken som en prövning som kan klaras av momentant och som liknar en examination eller tentamen, som vi som forskare "kallas upp till” när vi ska sätta igång ett projekt. Det finns, som jag ser det, en kontrast mellan den här prövningen å ena sidan och å andra sidan etiken som en process eller ett tänkande, en mer relationell etik som ligger närmare det som många forskare arbetar med i praktiken. Det gäller särskilt de som sysslar med kvalitativ forskning, etnografi till exempel, men även de som arbetar med enkäter och liknande. Där är etiken egentligen en del av kunskapsbildningen, för att uttrycka det högtidligt. Etiken borde därför vara en del av den vanliga metodundervisningen, som den ju också har varit. Som Sara påpekade har etiken börjat diskuteras på ett mer explicit sätt, och det hör ihop med annan iakttagelse tycker jag. Det gäller den specialisering eller avknoppning som har skett, med de här speciella råden och nämnderna. Ibland talas det om att man ska instifta lokala råd även på universiteten och fakulteterna. Specialiseringen och avknoppningen hör ihop med kontrasten mellan det lite mer inboxade sättet att se på etik gentemot det relationella, processorienterade och fältnära. Prövningen och specialiseringen är två sidor av samma mynt.

En tredje iakttagelse gäller det faktum att det har blivit svårt att kritisera den etiska kontrollen eller etiska regimen, om vi ska använda det ordet, i och med att kritik lätt kan tolkas som smitningsförsök. Man försöker komma undan den här etiska kontrollen, och det vill man inte, för man är ju för etik. Jag är också för etik och jag tycker det är lika viktigt som alla andra - med samtycke och konfidentialitet och hänsyn på alla möjliga sätt. Men jag tycker att det har blivit knivigt att kritisera den etiska kontrollen för att man lätt uppfattas som skum, eller som en etisk bov, för att låna ditt ord Sara. Det kan man också lägga märke till i vardagen i akademin. De här blanketterna och sättet att hantera den etiska prövningen är något som människor muttrar över, man förbannar kompletteringar och ordvrängningar eller uttryckssätt som man kanske tvingas använda utan att man riktigt förstår varför. Detta gör man lite i skymundan, som jag uppfattar det. $\mathrm{Nu}$ är detta seminarium ett exempel på motsatsen, att vi verkligen tar upp det. Men det är en sak att diskutera så här i allmänna termer och en annan sak att diskutera exempelvis en precis formulering i den blankett som jag håller på med. Det hade nog uppfattats som lite skämmigt, tror jag. 
Sociologisk Forskning: Det är ju intressant, därför att en anledning till att det här samtalet hålls är den här vardagsfrustrationen som forskare har, som ni nämner. Forskare sliter med etikblanketter, och många tycker att forskningsetiken är helt central, men kanske inte på det sätt som blanketten efterfrågar.

Sara nämnde Macchiarini-skandalen och många samhällsvetare uppfattar att etikprövningsformuläret är anpassat till medicinsk forskning och inte specifikt för det vi sociologer håller på med. Det här tar du också upp i din bok Sara, att det har gått från "disciplinsspecifika etiska koder" till övergripande förordningar. Vad skapar det system som finns nu för specifika problem för sociologer?

Jonas Edlund: Det är en märklig sak som jag har stött på, när det gäller det här CORS (Comparative Research Center Sweden) som vi har i Umeå. Vi har en nationell infrastruktur där vi samlar in data, inte för oss själva, utan för forskningssamhället. Det är helt fritt att använda dessa data. Om detta ska etikprövas i första skedet när man samlar in data, då hamnar man i problem med att det är en hel enkät som är gjord på internationell basis. Den kan innehålla hur många forskningsfrågor som helst i stort sett. Men etikprövningsnämnden kräver ju att man ska ha en väl definierad forskningsfråga för just de data man ska använda. Vi har kommit undan med det där, genom att trycka på att så länge vi inte använder data, samt lite andra saker också, så behöver vi inte etikpröva just den här infrastrukturen. Det finns säkert de som har andra åsikter om det. Det finns ännu inget klart rättsläge i den här frågan.

Det andra rör det som nämndes kring kvalitativa metoder, och att man kanske inte har en grundidé, utan att man som forskare vet kanske minst om det man forskar om i inledningsskedet. Det är samma sak för oss när vi ibland söker registerutdrag för olika variabler, alltså vi vet inte exakt vilka faktorer som kan vara viktiga, utan det kan finnas en lång rad. Sedan när man gör analyserna så ser man att det är de här områdena där det verkar ha stora effekter och då kan man inte gå vidare där, därför man har inte de nödvändiga variablerna. Även kvantitativ forskning innehåller ju en första fas som ofta är explorativ. Här är det inte helt lätt att anpassa den lista över variabler man faktiskt önskar till den specifika forskningsfråga man är tvungen att formulera. Dock måste jag säga att jag inte har varit i kontakt med Etikprövningsmyndigheten sedan den blev central. Mina erfarenheter är från tiden det var regionala etikprövningsnämnder. Jag tycker i och för sig att den som var i Umeå, där gick det ju att föra ett samtal. Det var en tidsödande process, men det var inte så att man kände att det var någon slags Kafka-relation och att man kommer dit och så får man avslag, utan det gick ändå att ha en dialog efteråt, och i slutändan så löste det sig. Men det är ett bökigt system och det är lite konstigt att det blir så här för samtidigt så ska inte Etikprövningsnämnden bedöma forskningens kvalitet. Men ändå blir det ju så, för om de ändå sitter och tänker att "den här forskningsfrågan var inte helt bra, exempelvis inte nog avgränsad”. Då blir det ändå indirekt så att de lägger sig i forskningen, som en slags överprövningsnämnd. 
Sociologisk Forskning: Ja, det är ju ett problem med forskningsprojekt där man har fått pengar och sedan kan man ändå få problem med etikprövningen, trots att ett projekt är godkänt av ett forskningsråd. David, det var du som skrev detta med att vi kanske vet minst i början av ett forskningsprojekt.

David Wästerfors: Ja, just det. Jag håller med dig, Jonas. Jag tycker också det ett bökigt system, och jag håller också med om din iakttagelse om att det inte är Kafka-artat egentligen. Det är förhandlingsbart och man får ofta igenom sina etikprövningar eller ansökningar till slut, så det är inte omöjligt. Men det är omständligt. Det påverkar väl sociologin på det sättet att man drivs ju åt att framställa projektet på ett visst sätt i blanketten och även i forskningspersonsinformationen, som är spikad på det sättet att man inte ska ändra den under projektets gång, vilket ju är ganska egendomligt om man ser till många sociologiska projekt som verkligen utvecklas under de år som man håller på med dem. Även då samtyckesrelationen kokas ner till den där blanketten som man ska dela ut och få underskriven. Det är inte riktigt det som man känner igen från de relationer som man kan skaffa med vissa informanter. Intresset för ens projekt kan växla ganska starkt och man kanske känner att personen i fråga är informerad vid en viss tidpunkt, men vid en senare tidpunkt så känner man verkligen inte att personen är informerad längre, personen ifråga kan helt ha glömt bort vad projektet handlar om. Då har man redan formellt klarat av detta genom underskriften i blanketten, så det tycker jag känns som en förvridning av den fältnära erfarenheten som sociologer och andra forskare kan ha. Sedan handlar det också om de här kontorsmiljöerna. Blanketter gör att man på något sätt får en känsla av att detta är den "riktiga" miljön för forskning, att forskningen sker i ett kontorssammanhang där man kan ha en blankett och en kulspetspenna. Det finns ju mycket forskning som faktiskt sker på gator och torg, när det regnar och blåser, i verkstäder eller på idrottsarenor, ja egentligen i massa olika sammanhang där den här blanketten inte riktigt passar in. Jag tycker också att det påverkar sociologer genom att etik blir en fråga om felsökande och kanske leder till en ganska negativ syn på etik. Det finns forskningsintressen som är etiskt försvarbara på det sättet att vi försöker synliggöra delar av samhället. Vi försöker uppmärksamma sociala problem eller fenomen lite varstans - på kontor eller utanför. Den etiska aspekten faller ofta bort i och med att man låser sig så hårt vid prövningen.

Sara Eldén: Jag tycker att Jonas och David har haft många bra synpunkter och funderar på vad jag har att tillägga. En sak är att den nuvarande etiska infrastruktur som vi har är kopplad till lagen. Det är därför vi har de här blanketterna, det är därför det ser ut på det sätt det gör. Min första egna erfarenhet av att etikpröva var i ett forskningsprojekt där jag skulle involvera barn. Inom den barnsociologiska forskningen finns det mängder skrivet om etik kring att forska med barn. Vi är väl medvetna om att det är en grupp som på olika sätt situeras - och är - utsatt. Jag var väldigt väl inläst på det här, men så fick jag den här blanketten framför mig och tyckte att de frågar ju över huvud taget inte om någonting av det som jag tyckte 
var viktigt eller om de etiska frågorna som jag hade, eller de dilemman som jag såg framför mig skulle kunna uppkomma. Då kände jag mig faktiskt både besviken och lite fundersam. Däremot frågade man om en massa saker som jag inte ens förstod vad det var, och som mest fick mig att känna mig inkompetent: hade jag missat vad det etiskt problematiska var i min studie? Tack vare goda kollegor, som David och andra, som delade med sig av erfarenheter, tog jag mig igenom det. Så då kommer vi in på här igen, att vi utvecklar en kompetens i att fylla i de här blanketterna på rätt sätt. Vi säger saker, som David sade, vi porträtterar ett forskningsprojekt på ett sätt som vi faktiskt vet inte helt överensstämmer med vad som kommer att hända i verkligheten, när vi är på fältet, för vi vet att fältet inte ser ut på det sätt som blanketten föreställer sig att det ser ut.

I efterhand diskuterade jag det med mina kollegor, alltså min besvikelse över varför jag inte fick diskutera dom där faktiska etiska problem i etikansökan. Varför fick jag inte berätta hur jättebra jag hade tänkt kring det här med kontinuerligt samtycke med barn och så vidare? Men vi kom till slutsatsen att jag nog faktiskt inte hade velat ha den diskussionen med Etikprövningsnämnden just därför att den är så styrd av lagen, den ska inte intressera sig för det, den ska bara kolla av att vi gör rätt enligt lagen. För även om, som ni säger, att det inte är en Kafkaprocess så är det ju fortfarande inte mycket av en dialog. Det är väldigt svårt att få till en dialog kring vad som är ett etiskt dilemma i ett projekt. Malin Thor Tureby (2019), som är muntlig historiker, skriver om hur hon försökte inleda en dialog med Etikprövningsnämnden och fick till svar att "vi kan inte prata med dig, vi ska inte ha en dialog med dig, vi examinerar dig", och det är ju på grund av deras lagstyrning.

Så vi lär oss den här kompetensen, och ja, jag tycker det är problematiskt att vi känner oss nödgade att porträttera ett forskningsprojekt på ett sätt som inte överensstämmer med det som äger rum sedan. Men en mer allvarlig konsekvens kan vara att vi faktiskt undviker att göra vissa saker. Det är problematiskt, om vi till exempel tänker att "vi struntar i att ha med barn i det här projektet", för det är så struligt. Vi undviker det, fast det egentligen skulle kunna vara väl så motiverat. Eller att vi undviker att ha med människor med olika typer av funktionsnedsättningar. Då leder det i förlängningen till att vi får forskning som inte blir lika bra, om vi låter vår oro för forskningsetikregimen styra oss på det sättet.

Dessutom, och återigen, när vi utvecklar den här kompetensen och blir duktiga på att prata om etik i det här stadiet innan vi genomför ett forskningsprojekt, så riskerar vi att missa den faktiska diskussionen om vad etik är. Vi riskerar att bli ganska ensamma i det som händer sedan, när vi kommer ut på fältet som kvalitativa forskare eller när vi har samlat in data, som du nämnde Jonas. Där vi kanske ser eller upplever potentiellt etiskt problematiska dilemman - vad gör vi då och vem hjälper oss där? Kan vi hantera relationerna på fältet? Vem ska vi prata med om det? Kan vi prata etik då också? För det är det som jag tycker är etik och det är där de viktiga etiska frågorna uppkommer. 
Sociologisk Forskning: Jag tänkte ta upp en mer praktiknära fråga, som knyter an till det du precis pratade om, Sara. Förra veckan hände det mig att en intervjuperson som ville vara med $i$ ett forskningsprojekt om arbetare på ett tvätteri tackade nej efter att hon läst informationsbrevet. Hon talar inte svenska och har haft en osäker anställning, och var en av dem på arbetsplatsen som jag verkligen ville nå. Jag fick veta att hon sade nej på grund av att hon hade blivit rädd av hur brevet var formulerat.

När detta hände hade jag redan formulerat en fråga till er om kontakten med respondenter och risken för att byråkratiskt språk i ett informationsbrev kan skapa misstro, eller till och med skrämma bort potentiella intervjupersoner. Det kanske särskilt gäller personer eller grupper som är ovana vid den här typen av språk eller har en misstro mot myndigheter och uppfattar språket som vi uppmanas att använda i informationsbrev som ett maktspråk. Vi avkrävs ju att ha en viss typ av tilltal. Detta är av särskild betydelse för en del av sociologin som handlar om att studera grupper utan makt eller med lite makt, och människor som befinner sig i olika utsatta situationer i samhället. Vad anser ni om det här, som vi som forskare måste förhålla oss till, som systemet ser ut nu?

David Wästerfors: Ja, det är komplicerat. Jag kan anknyta till det som du säger Sara med dialogen och jag har samma erfarenhet. Jag tycker att det är jättesvårt att föra en dialog. Om man nu tar exemplet som du lyfte här, Lena, och föreställer sig att man skulle ta upp den frågan med Etikprövningsmyndigheten. Jag tror det skulle vara väldigt svårt. Jag har gjort ganska många etikprövningar nu, även för doktorander, och jag skriver kortare och kortare. Jag känner inte alls igen mitt sätt att skriva när det gäller att skildra ett projekt. Så jag har nog också av strategiska skäl faktiskt tonat ner vissa problem som jag kanske till och med anat och i stället tagit upp dem i seminarieform. Så jag tycker inte alls att vi ska sopa dem under mattan. I det fall som du diskuterar nu Lena, där skulle man kunna tänka sig att köra med ett muntligt samtycke och förklara den här informationen på ett sätt som du upplever som lite mer fingertoppskänsligt. Det kan också ha sina etiska fördelar, även om det inte är helt klockrent att undvika blanketter heller, eller forskningspersonsinformation.

Men som sagt, dialogen med myndigheterna och blankettformen är inte så lätt att hantera. Jag känner själv att jag har blivit mer medveten om det som du säger Sara, att det är just lagreglerat och att de sitter och kollar att vi ska följa lagen. Problematiken i att samla in personuppgifter har ju diskuterats mycket och nu har vi ibland börjat rekommendera, skulle jag våga påstå, att man uttryckligen skriver att vi samlar inte in personuppgifter. Därmed skulle man kunna tänka sig att man kan hantera reglementet lite smidigare, alltså om man skriver att man vill nå någonting via människor, men inte människorna i sig. Jag tänker inte skriva listor på människor, deras egenskaper, personliga bakgrunder eller liknande, utan jag är ute efter sociala fenomen, berättelser, erfarenheter, relationer av olika slag. Det kan faktiskt vara ett sätt att försöka tydliggöra vad sociologin arbetar med. Där kan det finnas ett missförstånd också. Det kan vara att man uppfattar oss mer som att vi faktiskt gör register över människorna, när vi inte gör det. 
Jonas Edlund: Vad jag har kommit till insikt om under de här åren som jag har varit verksam, är att introduktionsbrevet, alltså det första brevet till respondenterna där man försöker förklara sin forskning, är oerhört viktigt. Det är viktigt hur det är utformat för att de ska förstå. Jag önskar ibland att man kunde bifoga en liten video eller någonting på tre minuter, där man kunde beskriva vad det är man ska göra. Vi har det här problemet att vi har så många bakgrundsvariabler. Den som inte riktigt vet hur forskningen fungerar, och inte vet hur man ställer upp tabeller eller hur man gör regressioner, kanske bara tänker när de ser frågan: "vad ska ni med det här till?” Det är en sak. Den andra är det här med hur man ska beskriva den tilltänkta forskningen. Jag har blivit som David, att jag försöker skriva väldigt kortfattat och ganska neutralt, ungefär som att all forskning inom det här projektet kommer att följa de forskningsetiska principer som finns för närvarande. Jag har sett vissa exempel på hur etikprövningsnämnden vill att informationen ska se ut och tänkt att väldigt många människor kan bli nervösa av något sådant. För det låter onekligen som att vi har möjlighet att sätta upp olika register och kolla upp vissa individer, men att de lagrum vi anger gör att vi avhåller oss från det. Den här förmedlade bilden överensstämmer verkligen inte med min bild av hur sociologisk forskning bedrivits, varken före eller efter GDPR. Det är otroligt viktigt hur introduktionsbrevet är utformat och att alla de här regelverken följs, men jag tror det är bättre att vi inte skriver ut om olika lagrum utan försöker skriva mer neutralt. Att skriva på byråkratspråk funkar inte.

Sara Eldén: Det här är en superviktig fråga och jag tycker att jag ser precis den här risken. Här igen ser vi hur vi försöker krumbukta oss ur och försöker hantera det här. För vi vet, igen, att praktiken ser ut på ett annat sätt, och som du beskrev så bra nu, Lena, så riskerar vi ganska mycket. Som kvalitativ forskare kan jag tänka på allt jobb vi lägger ner på att få en människa att känna sig trygg. Vi skapar förtroende i situationen. Vi ska få dem att känna att "du är viktig, jag vill ha din berättelse om detta. Det är viktigt." Sedan så måste den där blanketten upp då, och den ska skrivas under. Det är klart att man i en sådan situation, som den här personen som du beskriver Lena, ryggar tillbaka. Jag kan verkligen relatera till det, jag haft projekt där jag inte har kunnat involvera just människor i mycket prekära arbetslivssituationer, de har tackat nej för att de har blivit tveksamma.

Här igen så utvecklar vi en enorm kompetens som inte syns, en kompetens som vi måste besitta, som vi måste ha, för att våra projekt inte ska haverera. Ett exempel är mina barnforskningsprojekt. Jag har skrivit om det här i en artikel för några år sedan, hur jag som barnforskare måste jonglera samtycken när jag ska få ett barn att vara respondent. Det räcker inte med att barnet uttrycker samtycke. Det är en delikat process i sig att verkligen försäkra sig om att det här barnet vill vara med, att det inte känner sig övertalat av en förälder eller av någon annan. Samtidigt ska jag också jonglera förälderns samtycke. Jag ska då, utifrån ett barnforskningsperspektiv, framställa mig som att jag är intresserad av barnets röst, men föräldern eller andra vårdnadshavare kan ibland känna sig lite hotade av det, så jag måste också tona ner det. Jag måste använda en massa olika strategier för att hantera den där samtyckesblanketten som måste skrivas under. 
Jag tror att vi kanske ska våga tänka annorlunda. Vi har exempel på det i Lund, där några forskare har vågat hävda: "Nej, jag tänker inte ha en samtyckesblankett". Det framstår som att vi måste ha det enligt lagen, men de har faktiskt sagt till etikprövningsnämnden att "nej, det tänker jag inte ha". De har fått igenom det efter många vändor och har fått nämnden att förstå att en samtyckesblankett faktiskt inte är det mest etiska i alla sammanhang. Vi kanske måste våga börja stå upp för sådant här mer. Som i ditt projekt, Lena, det kan ju vara så att några respondenter kan tycka att det är helt okej att skriva under en samtyckesblankett, så som man har sagt i etikansökan, men så kommer en eller två som inte vill. Måste jag då skicka in en ändringansökan till etikprövningsnämnden för att sen inte i efterhand bli anklagad för att inte kunna visa upp att jag har samtycken? Jag tycker i slutändan att detta handlar om att min professionella kompetens som forskare inte räknas. Att jag inte anses kunna avgöra i en situation vad som är det mest etiska att göra i den situationen. Att jag inte skulle ha kollegor i ett seminarium att dryfta detta med, som kunde ge långt bättre råd än Etikprövningsmyndigheten.

David, du har ju för övrigt ett väldigt fint exempel i din artikel om etik (Wästerfors 2019) om vad man får säga och inte. Får man säga "tack"? Eller "din berättelse är viktig för mig"? Det får vi inte göra då, enligt regelverket, som David har beskrivit så bra i sin artikel. När det gäller många av de som jag intervjuar kan det vara otroligt viktigt att man får säga till dem att "din berättelse är jätteviktig”. För att de själva kanske inte riktigt ser det, för att det handlar om osynliggjorda grupper som inte alltid själva har känslan att "jag har något att säga om det här". Så igen, det är ett jonglerade och ett trixande och vi utvecklar nån slags kompetens kring det.

Sociologisk Forskning: Det här samtalet har ju visat på problem, dilemman och att många saker blir svåra i relation till hur vi jobbar etiskt som sociologer. Så jag vill avsluta med att fråga om man skulle kunna tänka sig att vi hade ett etikprövningssystem som utgår mer från sociologiska eller samhällsvetenskapliga forskningstraditioner och forskningspraktiker. Hur skulle det se ut? Vad är det vi behöver för etikprövning?

David Wästerfors: Det var en stor fråga. Jag tycker att det ska vara en del av metodologin. Man kan pröva idén med en etisk redogörelse. Många av de här etiska problemen blir som mest akuta när vi publicerar vårt material, och det är kanske då som vi måste redogöra för etiken i detalj. Det är också då som forskningen peer review-granskas, alltså då granskar vi varandras etik. Det skulle vara intressant att pröva att hantera etiken mer retrospektivt och inte bara prospektivt, som du var inne på Sara. Sen ska man naturligtvis också i ansökningar och liknande redogöra för sin etik "framåt", men det kanske är ännu viktigare att redogöra för hur det verkligen blev. Så att man inte riskerar att bara "checka av" etiken i början av projektet och sedan slappnar av och litar på att vi är "etiska". Så enkelt kan det väl rimligtvis inte vara och det borde vi förstå som sociologer. Man kan bygga in den retrospektiva redovisningen mer i seminarie- 
verksamheten eller publiceringen av studien och hålla den etiska debatten levande på det sättet. Sedan får man nog inse att de här reglerna är inte så lätta att undvika. Eller vad säger ni andra? Man kan ju vara sarkastisk mot dem men vi måste anpassa oss på något sätt och då handlar det också om att faktiskt utbilda de som prövar sociologiska projekt i de metoder som sociologer och andra samhällsvetare använder. Jag kan ändå få känslan av att det finns ett bildningsproblem där. Vissa kan nog, men vissa vet inte hur ett sociologiskt projekt kan utformas.

Jonas Edlund: Ja, jag är inne på samma sak. När man som forskare har ett projekt försöker man ställa sig frågan, och nu tänker jag igen då kvantitativt, "vad kan det här innebära för skada och vad kan det ge för nytta?". Vi var ju inne på detta med att undersöka utsatta grupper och det är ju ett dilemma. Å ena sidan, om vi inte hade fokuserat på skillnader i levnadsvillkor mellan män och kvinnor till exempel, då hade vi inte kunnat säga någonting om löneutveckling eller vem som tar ut föräldrapenning för att nämna några exempel. Sedan för de som har invandrarbakgrund har det blivit mer känsligt, då det kan användas politiskt från olika håll. Men vill man få kunskap om vissa grupper och deras levnadsvillkor, då måste man undersöka dem. Det är den typen av frågor jag tänker man ska ställa sig som forskare, vad konsekvenserna blir. Den frågan tror jag alltid man ska ställa sig. Men nu har det mer blivit det här mer med regler som vi försöker tänka på och att vi försöker krångla oss igenom systemet.

Jag tror också på, som David var inne på, det här att man bygger in det i undervisningen och i metodundervisningen, så att man skolar studenter - och oss själva - i att tänka på sådana här frågor i framtiden. Vad kan forskningen få för konsekvenser? $\mathrm{Nu}$ är det ju så att sociologisk forskning sällan får jättestora, vad jag vet, konsekvenser. Men sociologin hade faktiskt ett stort genomslag en gång $\mathrm{i}$ tiden. I slutet på sextiotalet när man började göra undersökningar kring befolkningens levnadsvillkor. Då var det sprängstoff när man såg de enorma skillnaderna som fanns mellan olika grupper. Det kan finnas fler exempel men det här är det jag kom att tänka på.

Sara Eldén: Det är en jätteviktig fråga. Vi kan ju sitta och kritisera och säga vad som är fel, men vi måste ju också börja tänka på vad kan vi göra. Vad skulle vi vilja se i stället? Jag tror att det är mycket viktigt att formulera det, faktiskt. Jag upplever, efter att jag kom ut med boken som du nämnde i början, ett enormt sug efter att diskutera de här frågorna. Vi kan hoppas att det finns en vilja också inom Etikprövningsmyndigheten och i hela systemet faktiskt, att ta in och fundera kring vad det blir för konsekvenser av nuvarande system? Och vad är det vi missar? Vad utgår vi från när vi formulerar de här reglerna och lagarna? Vad utgår vi från att forskning är? Som David säger så tror jag att det finns en okunskap många gånger. Att man tänker att en hypotetisk deduktiv metod, till exempel, det är det alla forskare använder sig av. Då är det lätt att förutse från början vilka variabler vi ska hantera. Men så ser ju inte all forskning ut. Då blir det extremt viktigt att hävda, särskilt från den sociologiska forskningen, att vi har en mängd olika metoder. Vi har en mängd olika empiriska fält som vi tittar på, och vad som definieras som risk, vad som kan vara potentiellt skadligt, kan se 
väldigt annorlunda ut för oss. Och vi är inte omedvetna om det. Vi måste hålla den diskussionen vid liv.

Jag tänker exakt som ni säger, att det här ska vara en naturlig del av hur vi lär oss om forskning och forskningsprocesser. I min bok har jag försökt tänka utifrån det, jag följer forskningsprocessen och pratar om olika etiska frågor och dilemman som vi kan ställas inför. "Vad är det för etiska frågor du kan ställas inför i forskningsprocessens olika skeden?". Vi måste utifrån ett mer omsorgsetiskt tänkande ställa oss frågor kring "vad kan bli ett etiskt problem?", som Jonas var inne på här också. "Vad kan bli etiskt problematiskt för den här gruppen? Vad kan bli etiskt problematiskt i mitt eget förfarande?”. Man kan också föreställa sig att vi skulle kunna ha en infrastruktur som svarar mot det. Jag tror på att, som David säger, bygga in det här i undervisningen, detta tänkande. Sedan måste vi kunna ha en modell när det gäller oss själva som forskare, om det ska vara i seminarieform eller på något annat sätt vet jag inte, men det måste bygga på andra frågor som dyker upp för en samhällsvetare. "Hur bygger man upp och bevarar förtroenden i fältarbeten?", till exempel. Det är en extremt svår och viktig etisk fråga. Eller "hur ramar vi in och rättvist skildrar den sociala värld vi försöker skildra i våra texter när vi skriver fram våra forskningsresultat?”. Det är inte en neutral process. Vad väljer vi för exempel? Hur skapar vi beskrivningar? En annan etisk fråga som vi pratar alldeles för lite om är vår egen säkerhet på fältet som forskare, som jag tyvärr tror kommer att behöva diskuteras mer. Vi har institutioner som står under säkerhetsbevakning. Hur kan vi skapa en säker miljö för en forskare på fältet?

Om man skulle föreställa sig någon typ av annan infrastruktur som inte bara är det här prospektiva kontrollerandet före, så tror jag att det skulle kunna vara möjligt. Men med nuvarande lagar och regleringar är det svårt. Den delen kanske alltid kommer att finnas där, för som David säger, nu har vi de här lagarna. Men vi borde kunna komplettera dem med någonting som faktiskt handlar om andra etiska frågor, av emergent natur, där det kan vara möjligt att också ingå i dialog kring etiska problem. En del av oss har turen att jobba på institutioner eller i forskargrupper där vi har ett väldigt bra pågående etiskt samtal, men jag tror många kan känna sig ganska ensamma när det händer saker på fältet till exempel. Det hoppas jag att vi kan ta tag i på något sätt. Jag tror inte på fler råd som kontrollerar, utan jag tror mer på att skapa andra, mer dialoginriktade infrastrukturer.

\section{Referenser}

Eldén, S. (2020) Forskningsetik. Vägval i sambällsvetenskapliga studier. Lund: Studentlitteratur.

Thor Tureby, M. (2019) "Makten över kunskapsproduktionen. Den institutionaliserade etikprövningen och humanistisk och kulturvetenskaplig forskning", Kulturella Perspektiv - Svensk etnologisk tidskrift 28 (1-2):17-29.

Wästerfors, D. (2019) "Den etnografiskt okänsliga etikgranskningen”, Statsvetenskaplig tidskrift 121 (2):173-205. 